\title{
CONHECIMENTOS, PRÁTICAS E VIVÊNCIAS DA SEXUALIDADE EM JOVENS SÃO-TOMENSES ${ }^{1}$
}

\author{
Flávio Castelo David dos Santos ANDRADE ${ }^{2}$
}

RESUMO: Neste artigo apresentamos alguns resultados preliminares da pesquisa que está a ser realizada na Faculdade de Psicologia e Ciências da Educação da Universidade do Porto (FPCEUP/CIIE) com o objetivo de identificar conhecimentos, práticas e vivências da sexualidade dos jovens São-tomenses e o papel da Educação Sexual Escolar (ESE) na adopção de comportamentos preventivos e saudáveis. Estudo qualitativo, exploratório, realizado através de um questionário de autopreenchimento, aplicado a 280 jovens, (135) rapazes e (145) raparigas entre os 15 e os 19 anos de idade, frequentando a $10^{\mathrm{a}}$ classe do ensino secundário em estabelecimentos públicos e privados. Resultados: observamos que há mudanças em curso no sentido de um maior controlo dos/as jovens estudantes sobre a sua vida sexual, nomeadamente através do prolongamento da idade de abstinência e da monogamia no namoro. $O$ início da atividade sexual é mais precoce nos rapazes ( 3 anos mais cedo do que as raparigas) e é mais observada, para rapazes e raparigas, quando não tem associada a relação de namoro. É de admitir a hipótese de que a ancoragem da prática sexual na relação afetiva possa ser protetora e libertadora, particularmente para as raparigas, do peso da identidade de género herdada, permitindo uma escolaridade mais prolongada e um projeto de vida mais autónomo.

PALAVRAS-CHAVE: Educação para a saúde. Educação sexual. Sexualidade juvenil. S. Tomé e Príncipe.

\section{Introdução}

Em São Tomé e Príncipe, a introdução da educação sexual em contexto escolar faz parte de uma estratégia-chave para alcançar os Objetivos de Desenvolvimento do Milénio $(\mathrm{ODM})^{3}(\mathrm{ONU}, 2000)$, especialmente o ODM 3 - promover a igualdade entre os géneros e a autonomia das mulheres, o ODM 5 - reduzir a mortalidade materna e ter acesso universal à saúde reprodutiva e o ODM 6 - combater o VIH e a SIDA. Neste

${ }^{1} \mathrm{O}$ artigo traz resultados de pesquisa relativas a projeto de Doutorado em Ciências da Educação na FPCEUP sob orientação da Doutora Cristina Rocha, da Faculdade de Psicologia e Ciências da Educação da Universidade do Porto (FPCEUP/CIIE) e do Doutor Gerhard Seibert da Universidade da Integração Internacional da Lusofonia Afro Brasileira (UNILAB) Bahia - Brasil.

${ }^{2}$ Doutorando em Ciências da Educação. FPCEUP - Faculdade de Psicologia e de Ciências da Educação da Universidade de Porto. Porto - Portugal. 4200-135 - davidflacas25@ hotmail.com.

${ }^{3}$ Cimeira do Milénio das Nações Unidas, realizada entre 6 e 8 de Setembro de 2000, em Nova Iorque, que ao analisar os maiores problemas mundiais, estabeleceu oito (8) Objetivos do Desenvolvimento do Milénio - ODM. 
âmbito, enquanto vertente da educação para a saúde, o ensino de educação para a sexualidade nas escolas são-tomenses procura interferir positivamente na promoção da saúde sexual e reprodutiva dos jovens.

Particularmente nos países mais pobres, como é o caso de São Tomé e Príncipe, a má saúde sexual e reprodutiva constitui uma importante parcela dos problemas de saúde que afetam e comprometem a vida de adolescentes e jovens ${ }^{4}$, como seja a gravidez na adolescência, o aborto não seguro, a infecção pelo VIH/SIDA e outras DST. Estes constituem um peso substancial sobre a vida da população jovem, das famílias e comunidades, a que se associa à escassez de recursos públicos de saúde.

Fazendo parte da vida, a sexualidade é universal e, ao mesmo tempo, singular para cada indivíduo; envolvendo aspectos individuais, sociais, psíquicos e culturais (HEILBORN, 1997, p.47). A dimensão cultural da sexualidade humana é ainda acentuada por Giddens (1996, p.17), para quem a sexualidade “[...] [d]eve ser encarada como a expressão de cada cultura e de cada época, uma vez que integra os valores e os padrões culturais de cada sociedade".

Para a Organização Mundial da Saúde (WHO), no ano de 1975, a sexualidade humana é um todo complexo, pessoal e social. Sendo definida como “[...] a integração de aspetos somáticos, emocionais, intelectuais e sociais do ser sexual, de maneiras positivamente enriquecedoras e que melhoram a personalidade, a comunicação e o amor" (WHO, 1975, p.6), abre espaço para ligar sexualidade, saúde e educação.

Se é por meio da educação que a pessoa pode alcançar a tomada de consciência de si e de sua realidade histórica e também fortalecer suas redes sociais (FREIRE, 1987; SEIDL, 2001), a sua importância para a promoção da saúde torna-se evidente, não só pelos conhecimentos específicos que oferece, mas sobretudo, porque pode melhorar as competências gerais, incluindo o desenvolvimento do pensamento crítico e das capacidades para tomar decisões (LOUREIRO; MIRANDA, 2010, p.132). Por isso, a educação em saúde constitui-se combinação de experiências de aprendizagem delineadas para desencadear ações conducentes à saúde (CANDEIAS, 1997).

Em suma, a educação para a saúde, onde se inclui a educação sexual em contexto escolar,

[...] é toda a atividade intencional conducente a aprendizagens relacionadas com saúde e doenças [...], produzindo mudanças no

\footnotetext{
${ }^{4}$ OMS/UNFPA/UNICEF (1999) define adolescência como o período da vida entre 10-19 anos, e os
} jovens como todos aqueles entre 10-24 anos. 
conhecimento e compreensão e nas formas de pensar. Pode influenciar ou clarificar valores, pode proporcionar mudanças de convicções e atitudes; pode facilitar a aquisição de competências; pode ainda conduzir a mudanças de comportamentos e de estilo de vida. (TONES; TILFOR, 1994, p.11).

Sendo a educação sexual uma componente da Promoção e Educação para a Saúde, a UNESCO considera que o objetivo primário da educação em sexualidade é

[...] equipar crianças e jovens com os conhecimentos, habilidades e valores para fazer escolhas responsáveis sobre seus relacionamentos sexuais e sociais num mundo afetado pelo VIH. Por isso, os programas de educação em sexualidade possuem, em geral, vários objetivos que se reforçam mutuamente: Aumentar conhecimentos e compreensão; Explicar e esclarecer sentimentos, valores e atitudes; Desenvolver ou fortalecer habilidades; Promover e sustentar comportamentos de redução de risco. (UNESCO, 2010, p.3)

\section{Sexualidade, gravidez na adolescência, abandono escolar e infecção HIV em São Tomé e Príncipe}

Desde 2001 que a sociedade são-tomense dispõe de informação que lhe permita apreender a magnitude dos problemas de saúde da população.

É neste contexto que surge o primeiro Inquérito Demográfico e Sanitário (IDS08-09) $)^{5}$. Neste evidencia-se que a prevalência do VIH entre os jovens dos 15 aos 24 anos é estimada em $0,8 \%$, sendo menos elevada entre os homens do que entre as mulheres $(0,1 \%$ e $0,6 \%$, respetivamente), correspondendo a um rácio de $60 \%$ entre homens e mulheres. Ou seja, entre os jovens de 15-24 anos, para cada 100 mulheres infetadas, existem 60 homens infetados (SÃO TOMÉ E PRÍNCIPE, 2010). O mesmo documento refere, ainda que a prevalência aumenta com a idade, sendo de 0,7\% na faixa dos 15-19 anos e de 0,9\% na faixa dos 20-24 anos. Esta tendência é, igualmente, observada nas mulheres, de $0,6 \%$ e $1,4 \%$ respetivamente. Todavia, nos homens, a prevalência diminui com a idade $(0,8 \%$ na faixa dos $15-19$ anos e $0.2 \%$ na faixa dos 20 24 anos). Na amostra de mulheres jovens de 15-24 anos que afirmam estar grávidas, a prevalência do VIH é de $0,8 \%$ contra $1 \%$ entre as que não estavam grávidas ou não sabiam do seu estado de gravidez (SÃO TOMÉ E PRÍNCIPE, 2010).

O mesmo documento menciona que as adolescentes (mulheres de 15-19 anos) constituem $21 \%$ do total das mulheres em idade de procriar, contribuindo:

5 Inquérito Demográfico e Sanitário (IDS-STP, 2008, 2009), publicado pelo Instituto Nacional da Estatística de São Tomé e Príncipe (SÃO TOMÉ E PRÍNCIPE, 2010). 
[...] para quase $10 \%$ da fecundidade total das mulheres [...] constatase que mais de duas adolescentes 15-19 anos, em cada dez (23\%), já começaram a vida fecunda: $17 \%$ já é mãe e $6 \%$ está grávida primeira vez. Aos 15 anos, mais de $3 \%$ das mulheres já tinha começado a sua vida fecunda, e esta proporção aumenta rapidamente com a idade: aos 17 anos, $23 \%$ das mulheres tem pelo menos um filho ou está grávida primeira vez e, aos 19 anos, esta proporção abrange cerca de $40 \%$ das mulheres, cuja grande maioria $(38 \%)$ já tem pelo menos um filho [...] a proporção de adolescentes que começou a vida fecunda varia de um mínimo de $19 \%$ no Centro para um máximo de $30 \%$ no Norte. O início precoce de vida reprodutiva é mais visível entre as adolescentes com o nível de instrução primário (36\%) do que entre as que têm o nível secundário ou mais (14\%). Do mesmo modo, nos agregados dos dois quintis mais pobres, a proporção de adolescentes que já começou a vida reprodutiva é muito mais elevada que nas do quintil mais rico (respetivamente, $37 \%$ e $39 \%$ contra $8 \%$ ). (SÃO TOMÉ E PRÍNCIPE, 2010, p.64).

Caller et al. (2010) afirma que a problemática da gravidez precoce não se deverá limitar a um assunto de informação, formação técnica e de condições socioeconómicas. Estes fatores são importantes, mas a grande questão é que esta problemática está imersa num universo de valores, modelos sociais, concepções sobre a sexualidade e os modelos comportamentais que colocam a mulher são-tomense numa posição marginal. Paradoxalmente, como refere Cohen (2011), num estudo recente, em:

[...] São Tomé e Príncipe existe toda uma cultura que não explica nem fala sobre género na pré-adolescência por um lado, mas promove género, sensualidade, erotismo através das novelas, danças e passagem de modelos, por outro. Neste ambiente as raparigas engravidam, abandonam a escola e em nove meses passam da infância para a fase adulta, muitas vezes num ambiente até então alheio. (COHEN, 2011, p.24).

\section{Implementação da educação sexual nas escolas são-tomenses}

Podemos considerar que a história da educação sexual em São Tomé e Príncipe é relativamente recente, pois inicia-se na década de 90 do século XX com o Decreto-Lei n. ${ }^{\circ} 67 / 95^{6}$ (SÃO TOMÉ E PRÍNCIPE, 1995). Sendo o primeiro documento legal publicado tendo como âmbito a educação sexual nas escolas, aparece encoberto pela designação "Projecto Introdução da Educação em Matéria de População e para a Vida Familiar nas Escolas (EMPVF ${ }^{7}$.

\footnotetext{
${ }^{6}$ Este Decreto-Lei surge durante a reforma do então Ministro da Educação, Juventude e Desportos, Guilherme Octaviano Viegas dos Ramos.

${ }^{7}$ Educação em Matéria de População e para a Vida Familiar nas Escolas.
} 
Do nosso ponto de vista a implementação deste diploma legal procurava introduzir a educação sexual nas escolas com o objetivo de preparar a nova geração para os problemas atuais em torno da sexualidade, nomeadamente o VIH/SIDA e a gravidez indesejada na adolescência.

$\mathrm{O}$ artigo $10^{\circ}$ deste diploma legislativo menciona especificamente que "[...] é institucionalizado o ensino em Matéria de População e para a Vida Familiar em todas as escolas secundárias básicas do País, abrangendo os níveis da 5. a $8 .^{a}$ Classes a partir do ano letivo de 1994" (SÃO TOMÉ E PRÍNCIPE, 1995, p.212). Já o artigo 2. estipula as disciplinas e classes onde devem ser ministradas estas matérias: a) 5. ${ }^{a}$ Classe - Estudos Sociais, Ciências Naturais e Língua Portuguesa; b) 6. ${ }^{a}$ Classe - Estudos Sociais, Ciências Naturais e Língua Portuguesa; c) 7. ${ }^{a}$ Classe - Geografia, Biologia e Língua

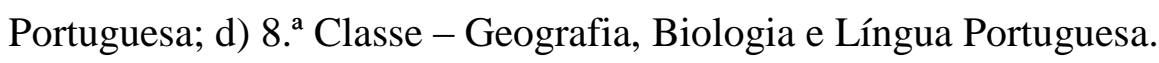

A primeira observação que parece ser possível fazer do artigo $2 .^{\circ}$ diz respeito ao facto da sexualidade ser abordada nas mais diversas disciplinas, não sendo atribuída exclusivamente aos Estudos Sociais, às Ciências Naturais e à Biologia, como seria esperado. Em suma, observa-se a preocupação das entidades governamentais em tornar a educação sexual em contexto escolar uma realidade devendo esta ser abordada numa perspectiva curricular ampla.

Por sua vez, o artigo 3..$^{\circ}$ estabelece que "os níveis de conhecimento das disciplinas a serem atingidos no ensino da Educação em Matéria da População e para a Vida Familiar, bem como os conteúdos didácticos são fixados por despacho do Ministério da Educação, Juventude e Desporto" (SÃO TOMÉ E PRÍNCIPE, 1995, p.212). Torna-se visível que a responsabilidade pela elaboração dos conteúdos didáticos é do governo.

Passados onze anos surge o Decreto-Lei n. ${ }^{\circ}$ 17/2006 de Junho ${ }^{8}$ (SÃO TOMÉ E PRÍNCIPE, 2006), o segundo documento legal publicado tendo como âmbito a educação sexual nas escolas, com uma intencionalidade claramente assumida, como se observa no 'Programa de Educação em Matéria de Saúde Sexual e Reprodutiva e Vida Familiar' (EMSSRVF).

$\mathrm{O}$ artigo $1 .^{\circ}$ deste novo diploma legislativo prevê a institucionalização do "Ensino de Educação em Matéria de Saúde Sexual e Reprodutiva e Vida Familiar (EMSSRVF) em todas as Escolas Primárias e Secundárias Estatais, assim como no

\footnotetext{
${ }^{8}$ Este Decreto-Lei surge na sequência do anterior e é levado a cabo pelo então Ministro da Educação, Cultura e Desporto, Jorge Lopes Bom Jesus.
} 
Instituto Superior Politécnico a partir do ano letivo de 2003/2004”. (SÃO TOMÉ E PRÍNCIPE, 2006, p.213).

As disciplinas e as classes nas quais podem ser lecionados os conteúdos relacionados com educação e saúde sexual estão previstas no artigo $2 .^{\circ}{ }^{\text {: }} 1$. $^{\text {a }}$ Classe Meio Físico e Social; 2. ${ }^{a}$ Classe - Meio Físico e Social; 3. ${ }^{a}$ Classe - Meio Físico e Social e Língua Portuguesa; $4{ }^{a}$ Classe - Meio Físico e Social e Língua Portuguesa; 5. ${ }^{\text {a }}$ Classe - Estudos Sociais, Ciências Naturais e Língua Portuguesa; 6. ${ }^{a}$ Classe - Estudos Sociais, Ciências Naturais e Língua Portuguesa; 7. Classe - Geografia, Biologia e Língua Portuguesa; 8. ${ }^{a}$ Classe - Geografia, Biologia e Língua Portuguesa. Na 9. ${ }^{a}, 10 .^{a} \mathrm{e}$ 11. Classes, como se pode ler no documento, "os conteúdos de EMSSRVF serão transmitidos em forma de conferência e palestras seguidas de debates". (SÃO TOMÉ E PRÍNCIPE, 2006, p.213).

$\mathrm{O}$ artigo acima exposto espelha uma ação legislativa mais significativa e incisiva no âmbito da educação sexual, na medida em que reforça a educação sexual formal no currículo escolar dos/as alunos/as, pois: antecipa o seu programa ao $1 .^{\circ}$ ciclo $\left(1 .^{\mathrm{a}}\right.$ a $4 .^{\mathrm{a}}$ classe) do ensino básico; mantém o seu ensino nos ciclos intermédios e determina que na 9. ${ }^{\mathrm{a}}, 10{ }^{\mathrm{a}}$ e $11 .{ }^{\mathrm{a}}$ Classes, já perante idades juvenis, os conteúdos da educação sexual sejam transmitidos em forma de conferência e palestras seguidas de debates; e determina ainda que a educação sexual deva ser abordada no ensino superior público.

É nosso entendimento que, em traços gerais, este Decreto-Lei n. ${ }^{\circ}$ 17/2006 (SÃO TOMÉ E PRÍNCIPE, 2006) atribuiu responsabilidades à esfera da educação sexual no que se refere à abordagem de temas relacionados com a vida e os problemas quotidianos, bem como de temas relacionados com o processo de crescimento pessoal e social das crianças, adolescentes e jovens, extravasando desta forma não só a função meramente informativa que a educação sexual pode assumir, como os professores enquanto interlocutores privilegiados, na medida em que abre a porta da escola aos demais especialistas conhecedores da temática, chamando-os para que contribuam na formação integral e harmoniosa das crianças, adolescentes e jovens são-tomenses nas questões que se relacionam com a saúde, direitos sexuais e reprodutivos, bem-estar familiar, entre outros domínios. Em suma, nestes dois documentos normativos há uma concepção de sexualidade que está associada à implementação de intervenções preventivas globais que procuram promover competências pessoais e sociais para a saúde e o bem-estar e a alteração das representações, valores e práticas relativas à sexualidade na cultura local. 


\section{Metodologia}

\section{Objetivos da investigação}

Temos como objetivo deste artigo apresentar alguns resultados preliminares de uma investigação mais vasta em curso no sentido de identificar conhecimentos, práticas e vivências da sexualidade dos jovens São-Tomenses e perceber, ainda, o papel da Educação Sexual Escolar na adopção de comportamentos preventivos e saudáveis, numa perspectiva de promoção da saúde.

\section{Método}

De forma a alcançar os objetivos da investigação e tendo em conta a complexidade do fenómeno social em causa, optou-se pela construção e aplicação de um questionário com perguntas abertas e fechadas e de autopreenchimento pelos/as jovens, como técnica de recolha de informação.

O questionário era composto por três partes: uma primeira parte de caracterização dos/as jovens contendo variáveis sociodemográficas, tais como o género, a idade, a escolaridade, a composição do grupo doméstico familiar. Uma segunda parte em que se procurava conhecer representações e práticas dos/as jovens sobre a sexualidade, através de perguntas como: "Tem namorado/a?"; "Já alguma vez teve relações sexuais?”; “Qual foi a sua intenção ao usar o método contraceptivo?”. Por fim, uma terceira parte, em que se procurava apreender os conhecimentos sobre sexualidade e o papel da educação sexual formal, não formal e informal na sua vida, através de perguntas como: "O que pensa acerca do ensino da educação sexual na escola?"; "Com quem você costuma conversar sobre género/sexualidade?”. Esta terceira parte integrava, ainda, dois conjuntos de afirmações/opiniões acerca da sexualidade masculina e feminina, acerca das quais se pede os/às jovens o seu ponto de vista sobre a sua veracidade.

O questionário foi aplicado em cinco escolas (públicas e privadas) de diversas regiões do País, como se observa na Figura 1, a 280 jovens, (135) rapazes e (145) raparigas, entre os 15 e os 19 anos de idade, frequentando a $10{ }^{a}$ classe do ensino secundário. As escolas foram identificadas através do Ministério da Educação Cultura e 
Formação. Os dados recolhidos por esse instrumento foram submetidos a uma análise descritiva (com recurso ao IBM SPSS versão 20) e a uma análise de conteúdo 9 .

Figura 1 - Mapa da Divisão Político-Administrativa (Distritos e Cidades) de São Tomé e Príncipe com escolas secundárias públicas e privadas onde se leciona a $10^{\mathrm{a}}$ classe e que foram objeto da pesquisa. Levantamento feito no ano letivo 2012-2013

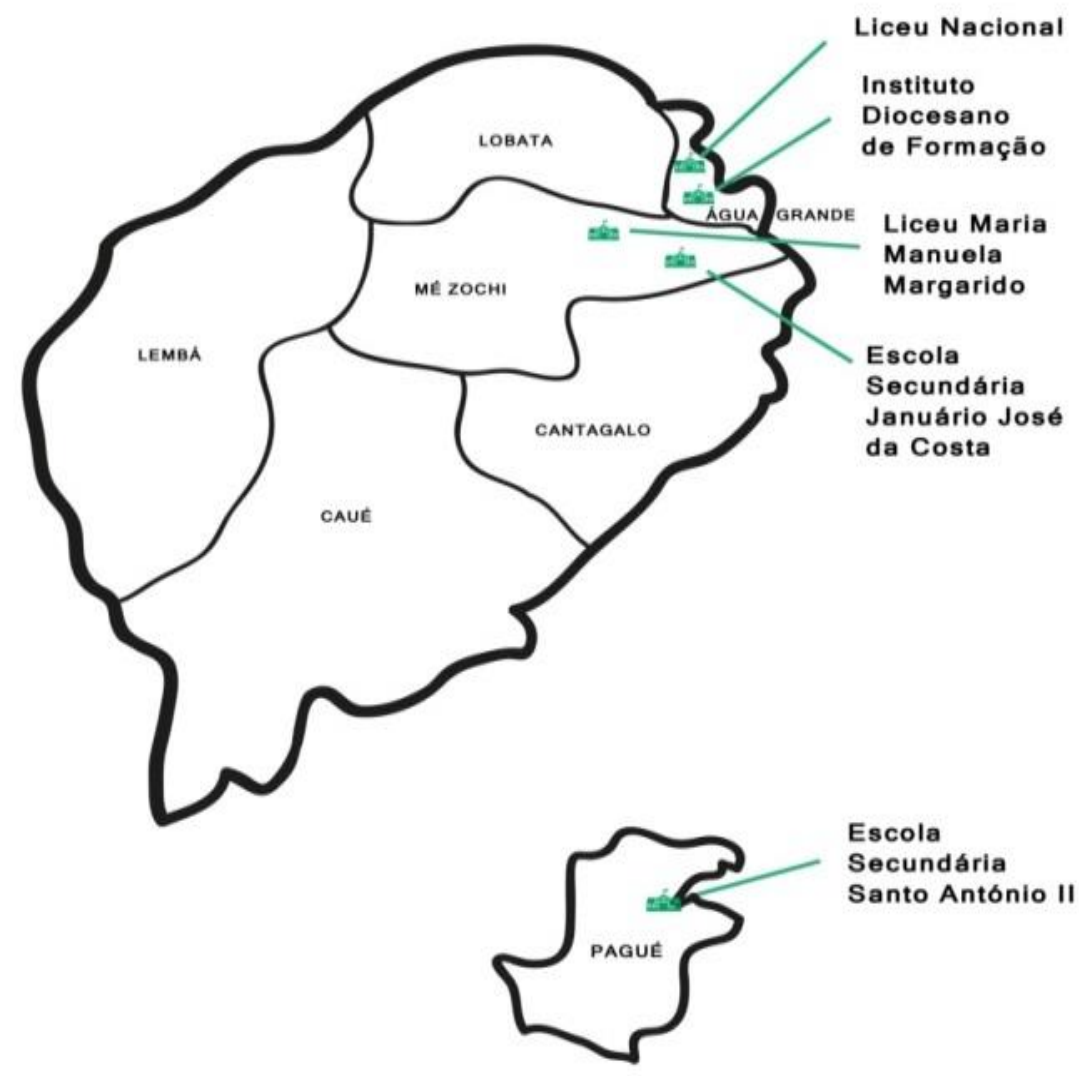

Fonte: Elaboração própria.

Pela análise do mapa, pode constatar-se que na altura em que se realizou a pesquisa, ano letivo 2012-2013, o sistema educativo são-tomense tinha quatro estabelecimentos de ensino onde se leccionava o $2 .^{\circ}$ ciclo (10. ${ }^{a}$ classe), encontrando-se todos concentrados em dois distritos, Mé-Zóchi e Água Grande, na ilha de São Tomé, e o quinto estabelecimento na ilha menor, Região Autónoma do Príncipe (Pagué).

\section{Amostra}

${ }^{9}$ Para a análise dos dados, utilizou-se a estatística descritiva (frequência, média, moda, etc.,), e aplicou-se o "Teste t" para a comparação das médias entre as variáveis género (rapazes e raparigas) e a idade de início da relação sexual, por serem as únicas variáveis numéricas (MUNDSTOCK et al., 2006). Recorremos, ainda, à análise de conteúdo: “[...] conjunto de técnicas de análise de comunicação, visando obter por procedimentos sistemáticos e objetivos de descrição de conteúdo”. (BARDIN, 2004, p.44). 
A amostra foi selecionada por conveniência ${ }^{10}$ entre os/as alunos/as do ensino secundário que frequentavam a $10 .^{\text {a }}$ classe nas escolas públicas e privadas. Num universo de 893 estudantes foram inquiridos $291^{11}$. A nossa amostra é constituída por 280 jovens estudantes, de ambos os sexos: 145 (51,8\%) do sexo feminino e 135 (48,2\%) do sexo masculino. No que se refere à área que frequenta, a maioria dos (as) participantes pertenciam a área das ciências e tecnologia, sendo 68 (50,4\%) rapazes e 67 (46,9\%) raparigas. Logo seguido pela área das línguas e humanidades, com 28 (20,7\%) rapazes e 44 (30,8\%) raparigas. A área sócioeconómico ocupa o terceiro lugar com 33 $(24,4 \%)$ rapazes e $30(21,0 \%)$ eram raparigas. A área menos numerosa é a artes visuais com $6(4,45)$ rapazes e $2(1,4 \%)$ raparigas. Houve duas participantes que não indicaram a sua área de estudo. Merece o destaque os factos de que as raparigas frequentam em maior número do que os rapazes a área de línguas e humanidades. A média de idades é de 17 anos ( $\mathrm{DP}=1,22$; mínima $=15$ e máxima $=19)$. Cerca de $45 \%$ viviam com os pais (e irmão/s), (50\%) era proveniente do distrito de Água Grande e 96,8\% dos/as participantes eram solteiros/as.

Em suma, a amostra compreende uma população de alunos/as do $2 .^{\circ}$ ciclo do ensino secundário que frequentam a $10 .^{\mathrm{a}}$ classe e que se caracteriza por serem:

- rapazes e raparigas jovens, com idades compreendidas entre 15 - 19 anos;

- alunos/as da $10^{a}$ classe, com percurso da educação sexual formal desde a $6^{\text {a }}$ classe;

- um grupo etário vulnerável e de risco face à gravidez indesejada, VIH, e outras DST;

- um grupo vulnerável, particularmente as raparigas, ao abandono escolar;

- informantes privilegiados sobre vivências e práticas de sexualidade juvenil e sobre a importância da educação sexual formal.

\section{Resultados e discussão}

Os resultados parciais que se apresentam foram seleccionados de cada uma das partes que constituem o questionário. Começamos pelas práticas sexuais juvenis.

\section{Práticas sexuais}

10 "O pesquisador seleciona os elementos a que tem acesso, admitindo que estes possam, de alguma forma representar o universo. Aplica-se este tipo de amostragem em estudos exploratórios ou qualitativos, onde não é requerido elevado nível de precisão”. (GIL, 1999, p.104).

${ }^{11}$ Foram excluídos 11 questionários: 2 pelo facto dos respondentes terem menos de 15 anos; 4 por terem mais de 19 anos; 5 por não ser indicada a idade. 
A prática de uma sexualidade ativa aparece como fazendo parte da vida destes/as jovens, como consequência do próprio processo de maturidade juvenil. À pergunta "Já teve relações sexuais" 46,4\% responderam "Sim". Porém, os rapazes praticam-na mais do que as raparigas: $60,70 \%$ dos rapazes participantes responderam que "Sim", enquanto só $31,10 \%$ das raparigas responderam afirmativamente. Podemos argumentar que o fato de os rapazes praticarem mais o ato sexual do que as raparigas sugere que na sociedade são-tomense existe uma cultura que protege os rapazes e que reprime mais as raparigas? Tal como constatou Cohen (2011, p.23), “[...] as críticas feitas às raparigas por parte dos adultos aquando da gravidez indesejada, denotam acusação e penalização, catalogando-as como as únicas responsáveis". Com efeito, como referem os estudos demográficos citados, a gravidez adolescente ocorre significativamente nesta faixa etária bem como o abandono escolar. Assim sendo, estes resultados não podem ser interpretados independentemente da idade dos/as respondentes e do ciclo de estudos que frequentam, pois sugerem, uma possível mudança em curso por parte das raparigas, que pertencendo à faixa etária em que se observa a nível nacional a maior incidência de gravidez adolescente e abandono escolar, não só se afirmam maioritariamente abstinentes como se encontram a prosseguir estudos. Ou seja, parecem indicar uma mudança no sentido de um maior controlo sobre as suas vidas e que se expressa através do controlo que exercem sobre a sua vida sexual, nomeadamente através do prolongamento da abstinência sexual.

É de realçar, ainda, que estes/as estudantes têm cerca de quatro anos em contato com a educação sexual formal, uma vez que começaram a abordar este tema, ainda que de uma forma muito incipiente, desde a $6 .^{\mathrm{a}}$ classe.

\section{Idade do início da vida sexual}

As diferenças de género voltam a marcar presença nas respostas sobre a idade do início da primeira relação sexual. Para os rapazes a primeira relação sexual ocorre cerca de três anos mais cedo (por volta dos 15 anos) do que as raparigas (por volta dos 17 anos) ${ }^{12}$. Quando solicitado com quem teve a relação sexual, não se encontrou grandes diferenças, 43,3\% dos rapazes respondem opção "Namorado (a)", comparativamente com $31,5 \%$ das raparigas.

${ }^{12}$ Os resultados do "Teste $\mathrm{t}$ " mostram que os rapazes iniciam a prática sexual significativamente mais cedo $(\mathrm{M}=\mathbf{1 4 . 9 8}, \mathrm{DP}=2.07)$ do que as raparigas $(\mathrm{M}=\mathbf{1 6 . 7 5}, \mathrm{DP}=1.60, t(128)=-5.060, \mathrm{p}<.001$. 
Os fatores que presidem à idade do início da atividade sexual são múltiplos, complexos e variáveis segundo as sociedades e as culturas sendo, ainda, interferidos pelos processos mais ou menos globalizados que concorrem para construir os/as crianças e jovens como categoria social própria. Por isso, qualificar como "precoce" o início da relação sexual é uma tarefa conceptualmente exigente pois está também eivada do modo como se definem as idades da vida - infância, juventude e adulta, e os seus atributos próprios e relativos. O INE/STP (SÃO TOMÉ E PRÍNCIPE, 2010, p.64) toma como referência a faixa etária 15-19 anos para aferir a gravidez e fecundidade adolescente. Já Caller et al. (2010, p.13) num estudo realizado para a UNICEF, sobre a problemática da gravidez e paternidade precoce em São Tomé e Príncipe, consideram a gravidez "precoce" quando ocorre entre 10 e 18 ou 12 e $18 \operatorname{anos}^{13}$.

Podemos também indagar se em São Tomé e Príncipe a idade precoce em que se dá o início da relação sexual estará associada, entre outros fatores, à estrutura e dinâmicas familiares locais e às condições habitacionais das famílias são-tomenses. Como refere Seibert (2001), muitas famílias vivem numa espécie de união de facto, um tipo de união localmente conhecida como «vivencha» que consiste em visitas regulares ou irregulares do cônjuge masculino às mulheres com quem estabeleceu uma relação sexual, regra geral uma jovem, e da qual resultou o nascimento de crianças ${ }^{14}$. Regra geral associa-se a esta informalidade conjugal de cariz "poligâmico", grupos domésticos monoparentais maternos, conflitualidade entre as mães que partilham o mesmo progenitor dos seus filhos, situações de pobreza, habitações precárias sem divisões internas, facilitando que as crianças e jovens desde muito cedo entrem em contacto com o mundo íntimo das relações dos adultos. Tal como constatou Cohen (2011, p.16), o facto de as casas não terem privacidade entre os quartos dos pais e dos filhos pode constituir um fator de influência relativamente à precocidade das relações sexuais ${ }^{15}$.

Contudo, esta precocidade não se observa nos/as jovens abrangidos pelo nosso estudo, pois mais de metade dos/as participantes relatam que iniciam a relação sexual

${ }^{13} \mathrm{O}$ referido estudo salienta que no caso das raparigas de 10 e 11 anos grávidas pode-se estimar que seu número é quase 0 .

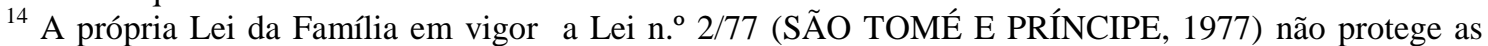
menores, visto que no seu artigo $3 .^{\circ}$, ponto 2 , menciona que os pais “[...] poderão autorizar, o casamento de menores de 18 anos, desde que a mulher já tenha completado os 14 anos de idade e o homem tenha completado os 16 anos de idade".

${ }^{15}$ A precocidade das relações sexuais, em idades infantis, é verificada na realidade angolana. Segundo o estudo do Fundo das Nações Unidas para a População (FNUAP, 2002), as relações sexuais iniciam-se entre os 11 e os 12 anos de idade, fazendo com que muitas adolescentes engravidem antes de atingir a idade adulta. 
entre os 15 e os 17 anos de idade, sendo que os 17 anos é a idade em que é predominante. Mais uma vez é de salientar que se trata de jovens estudantes a frequentar o $10^{\circ}$ ano de escolaridade, isto é, em que a barreira do abandono escolar precoce foi ultrapassada.

\section{Uso dos métodos contraceptivos}

Mais de metade dos/as jovens usou o preservativo na primeira relação sexual, e destes, os rapazes usaram-no mais do que as raparigas. No total, 64,3\% afirmaram ter usado o "preservativo" e 2,8\% ter praticado o "coito interrompido". Dos 64,3\% participantes que afirmaram ter usado o preservativo, $41,5 \%$ foram rapazes e $22,8 \%$ raparigas. Em conjunto, $67,1 \%$ das relações houve controlo da gravidez, embora o uso do preservativo tenha um espectro preventivo mais amplo ${ }^{16}$.

$\mathrm{Na}$ argumentação da maioria dos/as jovens participantes o não uso sistemático do método contraceptivo está associada, a ignorância/desinformação.- "Não tive muita informação sobre isso" é mais frequente na justificação dos rapazes, 17,6\% e contra $10,7 \%$ raparigas.

Procurámos perceber se os/os jovens participantes conversaram com o seu parceiro/a ou outra pessoa a cerca do uso do método contraceptivo aquando da primeira relação sexual e que justificassem as suas respostas. A argumentação da maioria deixa perceber que a razão desta conversa está associada à necessidade de obter "conselho" através da experiência dos outros. As raparigas são, mais do que os rapazes, afirmativas na busca de conselho antes da realização da primeira relação sexual, respectivamente $18,4 \%$ contra $13,8 \%$ dos rapazes.

O uso do preservativo na primeira relação sexual pelos/as jovens inquiridos, seja para a prevenção das DST seja para a prevenção da gravidez, simboliza, no nosso entender, um desejo e uma prática de descontinuidade face aos tradicionais hábitos sexuais dos são-tomenses que associam a sexualidade ao imperativo da reprodução, tal como está espelhada nos provérbios ou sabedoria popular são-tomenses como: "filho é riqueza dos pobres"; e /ou "viver com uma mulher sem ter filhos com ela é como estar a fazer um trabalho esforçado e no final não usufruir de uma remuneração"17. A

${ }^{16}$ A adopção deste comportamento verifica-se em diversos estudos sobre África (DA CUNHA; LUÍSA, 1997; UNICEF, 2011).

${ }^{17}$ São exemplos de provérbios ou sabedoria popular são-tomense que definem a moldura cultural de sexualidade, práticas sexuais e afetos masculinos. Parece-nos que estes provérbios, ou sabedoria popular, 
segunda observação que parece ser possível fazer desta posição dos/as jovens participantes diz respeito ao facto de manifestarem deste modo conhecimento e controlo sobre a contaminação das DST, bem como da gravidez.

\section{Conceito da sexualidade}

No sentido de captar algumas representações sociais acerca da sexualidade humana numa perspectiva diferencial de género e idade, dado a cultura de género sãotomense ser de longa data marcada por perfis acentuados de masculinidade $\mathrm{e}$ feminilidade tal como referem Caller et al. (2010, p.48), incluímos no inquérito afirmações várias que ora diferenciavam a sexualidade segundo o género e a idade do ser humano, ora a afirmavam independentemente destes, como: ' $\mathrm{Na}$ mulher a sexualidade começa na puberdade e termina após a menopausa'; 'Nos rapazes a sexualidade começa a partir da puberdade e não tem fase para terminar'; 'A sexualidade está presente em todas as fases de vida do ser humano'; 'Existe no homem e na mulher e tem idade específica para começar e para terminar'.

Verificou-se que são as raparigas $(41,4 \%)$, mais do que os rapazes $(33,9 \%)$ que consideram ser verdadeira a afirmação "A sexualidade está presente em todas as fases da vida do ser humano" denotando um maior descolamento da sexualidade do género e da idade e, por isso, uma inerência humana mais acentuada.

\section{Necessidade sexual}

Igualmente para tentar apreender perspectivas diferenciais de género acerca da necessidade sexual e em face de afirmações expressas como: 'Nos homens têm muito mais necessidades que as mulheres'; 'Nos homens têm um pouco mais de necessidades do que as mulheres'; 'Depende de cada homem e cada mulher; as mulheres têm um pouco mais necessidades'; 'As mulheres têm muito mais necessidades que os homens'.

No que respeita a necessidades sexuais, e em face da pergunta "Assinale com uma cruz as afirmações que considera verdadeira acerca das necessidades sexuais de homens e mulheres", verificou-se que a afirmação "depende de cada homem e de cada mulher" foi considerada verdadeira pela maioria dos/as $(73,8 \%)$. Merece destaque o facto de esta opção, segundo a qual que as necessidades sexuais dos homens ou das mulheres são inerentes à pessoa humana, independentemente do género, ser 
maioritariamente considerada verdadeira pelas raparigas $(77,2 \%)$ e pelos rapazes (70,4\%), sendo mais expressiva nas raparigas. Mais uma vez, são consideradas verdadeiras afirmações que acentuam dimensões da sexualidade humana numa perspectiva universalizante/individualizante, isto é, independente do género e da idade.

\section{Importância da educação sexual}

No que toca à percepção sobre a importância da educação sexual para a saúde, na sua vida e na vida em geral, e face à pergunta "Qual a importância que atribui à educação sexual na promoção da saúde das pessoas, verificou-se que as opções "Muito importante" e "Importante" perfazem, em conjunto para os rapazes, 47,5\% e em conjunto, 50,7\% nas raparigas. A justificação mais apontada sobre a importância da educação sexual na promoção da saúde das pessoas é da ordem da "capacitação". A argumentação em que se baseia acentua "Conhecimento, capacidade, saber”. Como refere uma jovem "Desenvolve a capacidade das pessoas, e ensina, as pessoas a terem mais cuidados e educação com a sexualidade”. Mais uma vez, a tradição e a cultura parecem estar a ceder lugar, na mente dos/as jovens, ao conhecimento científico veiculado pela escola. Uma vez que este conhecimento é acentuadamente de cariz preventivo, quando informa a ação dos/as jovens, cria uma margem de liberdade maior para controlarem a sua vida.

\section{Educação sexual formal, não formal e informal}

Os/as participantes da nossa amostra demostraram ter uma visão informada acerca da sexualidade humana, porquanto não revelaram alguma dificuldade em responder e mesmo argumentar as questões que lhes foram colocadas no questionário. Parece oportuno equacionar a hipótese de que a capacidade de respostas dos/as alunos/as participantes poderá estar relacionada com a educação sexual formal desenvolvida na escola e que, como referimos já, fez parte da escolaridade destes jovens desde a $6 .^{\mathrm{a}}$ classe.

\section{Quem lhe falou sobre a sexualidade}

Contudo, face à pergunta "Quem lhe falou pela primeira vez em sexualidade?”, verificou-se que a opção mais assinalada pelos 280 participantes foi "Amigos/as / colegas" 41,1\%, seguido de "Professor/a" 29,2\%, "Mãe/pai/pais" 23,6\%, e "outros" $6,1 \%$. Merece destaque o facto de que os pares foram a opção mais assinalada, 
independentemente do género dos/as participantes (rapazes 44,40\% e raparigas 37,90\%), mas com acentuação maior nos rapazes, vindo em seguida os Professores $(29,2 \%)$ (rapazes $26,70 \%$ e raparigas $31,70 \%$ ) com uma ênfase maior nas raparigas.

Podemos supor que esta prevalência mais acentuada dos/as professores/as como informantes das raparigas se deve ao facto de o corpo docente ser acentuadamente feminino, e que esta prevalência docente seja hipoteticamente uma influência conducente a um controlo maior das raparigas sobre a sexualidade.

\section{Fontes de educação sobre a sexualidade}

No que se refere a outras fontes de informação, livros e meios de comunicação social como rádio e TV, evidencia-se uma procura particularmente mais evidente nas raparigas, comparativamente com os rapazes, sobretudo no que se refere aos livros $(47,9 \%)$ e aos meios de comunicação social $30,7 \%$. Isto é as raparigas são as que recorrem mais às seguintes opções "livros", "TV- meios de comunicação" respectivamente, 57,2\%, 35,2\%. Quanto aos adultos de referencia, a "mãe” (30,3\%) assim como as "professoras/es" (29,7\%) e "profissionais de Saúde"(29,0\%) apresentam-se como agentes informativos equivalentes para auxiliar no processo de aprendizagem da educação sexual das raparigas. Enquanto nos rapazes "livros", "TVmeio de comunicação”, têm menor expressão, respectivamente, 37,8\% e 25,9\%; já a "mãe" se apresenta um adulto muito pouco significativo (16,3\%), ficando a sua influencia aquém da dos/as "professoras/es"(24,4\%) e "profissionais de Saúde" (28,1\%). Vale a pena, no entanto, assinalar que as opções "livros", e "TV-meio de comunicação”, perfazem $78,1 \%$. Estes resultados sugerem, tal como Gauntlett e Hill (1999) afirmam que no espaço público as tecnologias de informação e comunicação assumem um papel importante na aprendizagem da sexualidade e no desenvolvimento pessoal. As principais fontes de informação sobre a sexualidade para os/as jovens, tal como Leite (2001) também sustenta, são os livros, as revistas e os jornais, seguidos da televisão. Num mundo crescentemente globalizado, a circulação da informação é fortemente impulsionada pelos meios de comunicação social e pela internet, dispondo os/as jovens de São-Tomé e Príncipe, sobretudo dos contextos urbanos, acesso às suas múltiplas influências. 
Não obstante, os/as jovens consideram bastante relevante a existência da educação sexual nas escolas são-tomenses (muito importante 85,0\% e 13,2\% importante), independentemente do género dos participantes. No entanto, quando se observa distribuição da resposta por género, nesta matéria, ambos os géneros manifestam padrões semelhantes, 87,4\% dos rapazes, respondem "Muito importante", para $93,1 \%$ das raparigas. A atribuição desta importância vai ao encontro do estudo realizado pelo (ANGOLA, 1997, p.5) que sustenta que a educação sexual na escola pode promover a alteração do comportamento dos/as jovens, contribuindo para uma maior saúde sexual e reprodutiva.

\section{Considerações finais}

Observámos que há uma mudança em curso no sentido do que podemos considerar um maior controle dos/as jovens estudantes que frequentam a 10. ${ }^{\text {a }}$ classe, sobre as suas vidas e de libertação do peso das identidades de género herdadas assentes na sexualidade precoce, na gravidez adolescente -, associadas à propagação das DST, nomeadamente VIH, que se expressa através do autodomínio que denotam exercer sobre a sua vida sexual, nomeadamente através do prolongamento da abstinência e da monogamia no namoro. Esta mudança em curso percepciona-se, como vimos, mais acentuada por parte das raparigas. Com efeito, ao analisar o início da atividade sexual constatámos que é mais precoce nos rapazes (três anos mais cedo do que as raparigas). Constatámos também que ignorância/desinformação constituem a maioria dos argumentos dos jovens participantes, face ao não uso do preservativo. Mais uma vez, são os rapazes que acentuam a desinformação. Por outro lado, constatámos que são maioritariamente as raparigas quem pedem conselhos sobre o uso do método contraceptivo antes de iniciar a relação sexual.

Das alterações que se verificam em matéria de sexualidade juvenil destaca-se a procura de Livros e TV como fonte da informação para a aprendizagem da educação sexual. Merece destaque o facto de que nas raparigas se evidencia uma procura particularmente mais evidente.

Existe consenso entre rapazes e raparigas acerca da importância da educação sexual formal, reconhecendo que esta promove o desenvolvimento de atitudes e comportamentos responsáveis no domínio da sexualidade. Também se tornou visível que continua a ser entre pares, com os amigos/as ou colegas, que a comunicação sobre a 
sexualidade é mais acentuada. Os adultos são também significativos, nomeadamente a figura materna, mas mais para as raparigas do que para os rapazes.

\section{KNOWLEDGE, PRACTICES AND EXPERIENCES OF SEXUALITY IN SAO TOME YOUNG PEOPLE}

ABSTRACT: In this paper we present some preliminary results of the research that is being conducted in order to identify knowledge practices and experiences of sexuality of S. Tomé e Príncipe young people, and the role of School Sex Education (ESE) to take preventive and healthy behaviors. Qualitative study through a self-completion questionnaire with 280 young people - boys (135) and girls (145) -, between 15 and 19 years old, attending the 10th year of secondary education in public and private establishments. Results: we note that there are ongoing changes towards greater control of young people about their sexual life, including through the extension of age abstinence and monogamy in dating. The onset of sexual activity is earlier in boys (3 years earlier than the girls) and is more observed, for boys and girls, when they have not been associated with relationship dating. It is admitted the hypothesis that in São Toméan context the sexual practice based in the affective relationship can be protective and liberating, particularly for girls, of the weight of inherited gender identity, allowing a longer education and a more autonomous life project.

KEYWORDS: Health education. Sex education. Adolescent sexuality. S. Tomé and Príncipe.

\section{REFERÊNCIAS}

ANGOLA. Ministério da Saúde. Programa Nacional de luta contra a SIDA/UNAIDS SIDA. Perfil do país resposta nacional. Luanda: Ministério da Saúde, 1997.

BARDIN, L. Análise de conteúdo. 4.ed. Portugal: Edições 70, 2004.

CALLER, J. M. et al. A problemática da gravidez e paternidades precoce em São Tomé e Príncipe: diagnóstico da situação Relatório de um estudo financiado pelo PNUD e UNICEF em São Tomé e Príncipe, 2010. São Tomé e Príncipe: UNICEF, 2010 .

CANDEIAS, N. M. Conceitos de educação e de promoção em saúde: mudanças individuais e mudanças organizacionais. Revista de Saúde Pública, São Paulo, v.31, n.2, p.209-213, abr. 1997.

COHEN, G. A gravidez precoce: estudo qualitativo sobre conhecimento, atitudes e práticas relacionadas com a sexualidade e gravidez entre os adolescentes e jovens em São Tomé e Príncipe. São Tomé e Príncipe: Médicos do Mundo, 2011. 
DA CUNHA; LUISA, M. Mobilization to protect homeless adolescent CSW and single homeless mothers in Maputo. 1997. Disponível em:

<www.aegis.com/pubs/aidsline/2003/dec/m03c0910.html>. Acesso em: 17 nov. 2014.

FNUAP. Fundo das Nações Unidas para a População. Apoio FNUAP Angola 2002. O que precisamos saber? Manual de apoio aos profissionais amigos dos jovens. Luanda: FNUAP, 2002.

FREIRE, P. Pedagogia do oprimido. Rio de janeiro: Paz e Terra, 1987.

GAUNTLETT, D.; HILL, A. TV living: television, culture and everyday life. London:

Routledge, 1999.

GIDDENS, A. Transformações da intimidade: sexualidade, amor e erotismo nas sociedades modernas. Oeiras: Celta editora, 1996.

GIL, A.C. Métodos e técnicas de pesquisa social. 5.ed. São Paulo: Atlas, 1999.

HEILBORN, L. Corpo, sexualidade e género. In: DORA, D. (Org.). Feminino e masculino: igualdade e diferença na justiça. Porto Alegre: Sulina, 1997. p.47-57.

LEITE, A. P. L. Sexualidade na adolescência: conhecimentos, atitudes e práticas dos adolescentes estudantes do município de Maceió. Revista Brasileira de Ginecologia e Obstetrícia, Rio de Janeiro, v.23, n.2, p.124, 2001. Disponível em:

<http://www.scielo.br/pdf/rbgo/v23n2/11379.pdf>. Acesso em: 29 jun. 2012.

LOUREIRO, I.; MIRANDA, N. Promover a saúde: dos fundamentos à acção.

Coimbra: Edições Almedina, 2010.

MUNDSTOCK, E. et al. Introdução à análise estatística utilizando o SPSS 13.0. Porto Alegre: Universidade Federal do Rio Grande do Sul, 2006. Disponível em: <http://www.mat.ufrgs.br/ camey/SPSS/Introdu\%E7\%E3o\%20\%E0\%20An\%E1lise\%2 0Estat\%EDstica\%20utilizando\%20o\%20SPSS\%2013_0.pdf >. Acesso em: 17 nov. 2014.

OMS. ORGANIZAÇÃO MUNDIAL DA SAÚDE. Saúde reprodutiva de adolescentes: uma estratégia para ação: uma declaração conjunta da OMS/UNFPA/UNICEF. Genebra: OMS, 1999.

ONU. ORGANIZAÇÃO DAS NAÇÕES UNIDAS. Objetivos de Desenvolvimento do Milénio. [S.1.]: ONU, 2000.

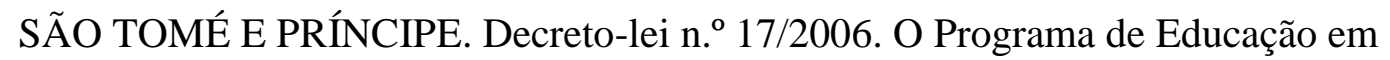
Matéria de Saúde Sexual e Reprodutiva Vida Familiar (EMSSRVF). Diário da República de São Tomé e Príncipe, n.22, 21 jun. 2006.

. Decreto-lei n. ${ }^{\circ}$ 67/95. Cria o Projeto Introdução da Educação em Matéria de População e para a Vida Familiar nas Escolas EMPVF). Diário da República de São Tomé e Príncipe, n.15, 31 dez. 1995.

Lei $n^{0}$ 2/77 regula juridicamente as intituições de familia. : São Tomé e Príncipe: Assembleia Popular de São Tomé e Príncipe, 1977. 
Ministério da Saúde e ICF Macro. 2010. Inquérito Demográfico e Sanitário, São Tomé e Príncipe, IDS STP, 2008-2009. Calverton: Instituto Nacional de Estatística de São Tomé e Príncipe (INE/STP), 2010.

SEIBERT, G. Camaradas, clientes e compadres: colonialismo, socialismo e democratização em São Tomé e Príncipe. Lisboa: Vega, 2001.

SEIDL, E. M. F. Pessoas vivendo com HIV/aids: configurando relações entre enfrentamento, suporte social e qualidade de vida. 2001. 365f. (Doutorado em Psicologia) - Universidade de Brasília, Brasília, 2001.

TONES, K.; TILFORD, S. Health education. Effectiveness, efficiency and equity. London: Chapman Hall, 1994.

UNESCO. UNITED NATIONS EDUCATIONAL, SCIENTIFIC AND CULTURAL ORGANIZATION. Razões em favor da educação em sexualidade: orientação técnica internacional sobre educação em sexualidade. Brasília: UNESCO, 2010. Disponível em: <http://unesdoc.unesco.org/images/0018/001832/183281por.pdf>. Acesso em: $19 \mathrm{dez}$. 2014.

UNICEF. Análise de situação da criança e adolescente em Cabo Verde. Consultoria externa: Márcio Carvalho. Cabo Verde: Gráfica da Praia, 2011.

WHO. WORL HEALTH ORGANIZATION. Education and treatment in human sexuality: the training of health professionals, report of a WHO meeting [held in Geneva from 6 to 12 February 1974]. World Health Organization technical report series, Geneva, n.572, 1975. Disponível em:

<http://apps.who.int/iris/handle/10665/38247>. Acesso em: 20 dez. 2014. 